\title{
Characterization and Rheological Behavior of Dextran from Weissella confusa R003
}

\author{
Siwames Netsopa (iD, ${ }^{1}$ Suwanna Niamsanit, ${ }^{2}$ \\ Duangkamon Sakloetsakun, ${ }^{3}$ and Nipa Milintawisamai ${ }^{1}{ }^{1}$ \\ ${ }^{1}$ Department of Biochemistry, Faculty of Science, Khon Kaen University, Khon Kaen 40002, Thailand \\ ${ }^{2}$ Department of Microbiology, Faculty of Science, Khon Kaen University, Khon Kaen 40002, Thailand \\ ${ }^{3}$ Faculty of Pharmaceutical Sciences, Khon Kaen University, Khon Kaen 40002, Thailand \\ Correspondence should be addressed to Nipa Milintawisamai; nipmil@kku.ac.th
}

Received 17 January 2018; Revised 26 March 2018; Accepted 5 April 2018; Published 15 May 2018

Academic Editor: Arthur J. Ragauskas

Copyright (C) 2018 Siwames Netsopa et al. This is an open access article distributed under the Creative Commons Attribution License, which permits unrestricted use, distribution, and reproduction in any medium, provided the original work is properly cited.

\begin{abstract}
Dextran from Weissella confusa R003 isolated from sugar cane juice was purified and characterized. Dextran synthesis was performed by fermenting $W$. confusa R003 in MRS medium containing 10\% (w/v) sucrose with continuous shaking at $125 \mathrm{rpm}$ and at $30^{\circ} \mathrm{C}$. For 24 hours, the $50 \%$ efficiency yield was obtained. Dextran in the culture medium was purified by ethanol precipitation. Structural analysis of dextran using ${ }^{1} \mathrm{H}$ NMR, ${ }^{13} \mathrm{C}$ NMR, and 2D NMR techniques showed the existence of glucoses with $97.4 \% \alpha$ $(1 \rightarrow 6)$ linkage in the main chains and $2.6 \% \alpha(1 \rightarrow 3)$ in branches. The estimation of molecular weight by dynamic light scattering exhibited average molecular weight of $1.0 \times 10^{4} \mathrm{kDa}$. At low concentration $(2.5 \% \mathrm{w} / \mathrm{v})$, dextran behaved like liquid structure, while, increasing the concentration $(5.0$ and $10.0 \% \mathrm{w} / \mathrm{v})$, it was revealed as viscoelastic behavior. The highest gelling phenomenon was found in the concentration of $10 \% \mathrm{w} / \mathrm{v}$ and at $37^{\circ} \mathrm{C}$. Due to its production and properties, it may be suitable for commercial production and application in the field of foods as well as hydrogel.
\end{abstract}

\section{Introduction}

Dextran is a homopolysaccharide (HoPS) consisting of Dglucose units linked by $\alpha(1 \rightarrow 6)$ glycosidic bonds in more than $50 \%$ of the main chain and generally branched with $\alpha(1 \rightarrow 2), \alpha(1 \rightarrow 3)$, or $\alpha(1 \rightarrow 4)$ glycosidic linkages $[1,2]$. Synthesizing dextran via biosynthesis can be done by using lactic acid bacteria (LAB) such as Leuconostoc, Lactobacillus, Streptococcus, and Weissella $[1,3,4]$. These bacteria are able to secrete dextransucrase, which synthesizes dextran by transferring glucose residues from sucrose to the reducing tail of growing chains [5]. Thus, dextrans are varied in their chemical structure, molecular weight, as well as branch linkage pattern depending on the bacterial strain $[4,6,7]$. This results in variable rheological behavior of dextran.

Today, several biopolymers including dextran are used commercially. Not only native dextran but also dextran derivatives have received attention for applications in food, pharmaceuticals, chemicals, cosmetics, and frozen dairy products [1, 8-10]. Additionally, several biopolymers including dextran are utilized as hydrogels, especially in the field of tissue engineering where they are used as matrices to repair and regenerate deteriorated tissues and organs [11].

Due to their unique properties that can regulate the rheological behavior of the final product, dextrans have been used in manufacturing [12]. Dextran, especially for food applications, was originally overlooked due to its high solubility or lack of viscosity, so other biopolymers have been widely used for of their thickening and gelling properties [13]. Most aqueous dextrans are non-Newtonian pseudoplastic materials in which the viscosity always decreases while the shear rate increases. In previous studies, $5.0 \mathrm{mg} / \mathrm{mL}$ aqueous dextran from Pediococcus pentosaceus and L. mesenteroides NRRL B-640 have shown non-Newtonian pseudoplastic behavior when shear rates of $0.05-500 \mathrm{~s}^{-1}$ and $0.1-1000 \mathrm{~s}^{-1}$ were applied, respectively $[14,15]$. Moreover, the aqueous dextran produced by $L$. mesenteroides with a molecular weight between $1.74 \times 10^{8}$ and $4.41 \times 10^{8} \mathrm{Da}$ exhibits pseudoplastic 
behavior in the shear field [16]. At high concentrations, aqueous dextran is a viscoelastic material. Padmanabhan has reported that, using dynamic frequency sweep, $250 \mathrm{mg} / \mathrm{mL}$ dextran from L. mesenteroides NRRL B-523 is an entangled biopolymer in which solid-like behavior dominates in the high frequency range while liquid-like behavior dominates in the low frequency range [12].

In various applications, such as blood plasma substitution, low molecular weight $40-100 \mathrm{kDa}$ dextran is suitable [17]. Foods and hydrogels, however, need high viscosity dextran, which means adding low molecular weight dextran to increase the viscosity of the final product. Consequently, dextran that exhibits more gel-like behavior or high viscosity is preferable for commercial applications since the amount used is minimal; thus, the cost is reduced. The common factors that affect dextran viscosity are molecular weight and branch linkages.

Generally, dextrans from the genus Weissella are highly linear with few branches. Based on a previous report, $W$. confusa E392 produces dextran, composed of $97.3 \% \alpha(1 \rightarrow 6)$ linear linkages and $2.7 \% \alpha(1 \rightarrow 3)$ branch linkages [4]. $W$. confusa Cab3 dextransucrase synthesizes dextran with $97 \% \alpha$ $(1 \rightarrow 6)$ and $3 \% \alpha(1 \rightarrow 3)$ linkages [18], whereas $W$. cibaria CMGDEX3 produces a linear dextran with $3.4 \% \alpha(1 \rightarrow 3)$ branch linkages [1]. Dextrans from the genus Weissella sp. have been studied, but the rheological properties are rarely mentioned. Aqueous dextran may exhibit different rheological characteristics depending on the molecular weight, branch linkages, concentrations, and testing temperature. Therefore, further understanding about polymer rheology must be conducted to allow for precise applications.

In this work, we present the properties of dextran from a new strain, $W$. confusa R003, which was isolated from sugar cane juice. The dextran from this strain was selected due to its high viscosity, which causes problems in sugar production. The dextran was produced and purified, and the structure was analyzed using ${ }^{1} \mathrm{H}-\mathrm{NMR},{ }^{13} \mathrm{C}-\mathrm{NMR}$, and 2D NMR spectroscopy. The molecular weight and surface morphology were evaluated. Importantly, the rheological properties and factors affecting its rheological behavior were also determined.

\section{Materials and Methods}

2.1. Materials. Dextran T2000 and standard dextran $1-670 \mathrm{kDa}$ were purchased from Sigma. All other chemicals in this research were of analytical grade.

2.2. Bacterial Strain and Identification. The bacterial strain was isolated from sugar cane juice from the sugar industry in Thailand by Milintawisamai et al. (2009) [19]. The strain was stored at $-70^{\circ} \mathrm{C}$ until use. The bacterial strain was identified by $16 \mathrm{~S}$ rDNA gene sequencing analysis [20]. The two sets of primers were 27F $\left(5^{\prime}\right.$-AGA GTT TGA TCM TGG CTC AG-3')/800R ( $5^{\prime}$-TAC CAG GGT ATC TAA TCC- $\left.3^{\prime}\right)$ and 518F ( $5^{\prime}$-CCA GCA GCC GCG GTA ATA-3')/1492R ( $5^{\prime}$-TAC GGY TAC CTT GTT ACG ACT T- ${ }^{\prime}$ ) to give two partial sequences; overlapping provided the full-length sequence. The full sequence of $16 \mathrm{~S}$ rDNA gene was aligned using the
NCBI database. The gene sequence of Weissella confusa R003 was submitted to the GenBank database.

2.3. Dextran Production. W. confusa R003 was cultured in modified De Man, Rogosa, and Sharpe (MRS) medium [21] containing (g/L) sucrose, 100.0; Bacto-peptone, 10.0; yeast extract, $4.0 ; \mathrm{K}_{2} \mathrm{HPO}_{4}, 2.0$; meat extract, $8.0 ; \mathrm{MgSO}_{4}$ $\cdot 7 \mathrm{H}_{2} \mathrm{O}, 0.40 ; \mathrm{MnSO}_{4} \cdot \mathrm{H}_{2} \mathrm{O}, 0.05 ; \mathrm{CH}_{3} \mathrm{COONa} \cdot 3 \mathrm{H}_{2} \mathrm{O}, 8.29$; $\left(\mathrm{NH}_{4}\right)_{2} \mathrm{C}_{6} \mathrm{H}_{6} \mathrm{O}_{7}, 2.0$; Tween 80, 1.0. The $\mathrm{pH}$ of the medium was adjusted to 7.5 before sterilization at $121^{\circ} \mathrm{C}$ for $15 \mathrm{~min}$. W. confusa $\mathrm{R} 003$ was incubated in MRS at $30^{\circ} \mathrm{C}$ with a shaking rate of $125 \mathrm{rpm}$ for $24 \mathrm{~h}$. Time course of dextran production was monitored from culture medium for 0 to 48 hours. Dextran was monitored by collecting culture medium by centrifugation at $6000 \mathrm{~g}$ for $20 \mathrm{~min}$ in order to remove the bacterial cell in the first step and then precipitating by chilled ethanol according to the method of Sarwat et al. (2008) in the second step [8]. The precipitated dextran was dried and weighed. The cell growth was monitored by a UVVis spectrometer at $600 \mathrm{~nm}$. Sucrose content was monitored by high-performance liquid chromatography (HPLC). The samples were prepared and subjected to LC-20AB and SIL20A autosampler system (Shimadzu, Japan). The sugar was separated by Shodex Asahipak NH2P-50 4E at $40^{\circ} \mathrm{C}$ using water and acetonitrile $(35: 65)$ as the mobile phase. The flow rate was fixed at $1 \mathrm{ml} / \mathrm{min}$ and the elution was monitored by a RID-10A refractive index detector (Shimadzu, Japan).

2.4. Purification of Dextran. Dextran was harvested from the culture of $W$. confusa R003 at 24 hours and then precipitated the culture medium by chilled ethanol according to the method described by Sarwat et al. (2008) [8]. The ratio of supernatant per ethanol was modified from the method described by Sarwat et al. (2008) from the ratio of $1: 1$ to $3: 2$. After adding chilled ethanol, the solution was vigorously stirred with a magnetic stirrer until the precipitate appeared. The precipitated dextran was redissolved in distilled water and then precipitated again as mentioned above. This step was repeated twice in order to remove the impurities. The purified dextran was subjected to drying by freeze drying processes which were performed by a ScanvacCoolSafe Freeze Dryer (LaboGene, Denmark).

2.5. Scanning Electron Microscopy (SEM). The freeze dried dextran was subjected to SEM. The $100 \mathrm{mg}$ of the purified dextran was scattered on stubs and fixed by double sided tape, respectively. The sample was coated with gold particles using the current of $20 \mathrm{~mA}$ for $3 \mathrm{~min}$. The surface morphologies were investigated using a SNE-4500M desktop scanning electron microscope (SEC) by applying the voltage at $15 \mathrm{kV}$.

2.6. Estimation of Molecular Weight. The molecular weight of the purified dextran was determined by high-performance liquid chromatography (HPLC) and dynamic light scattering (DLS). HPLC was carried out using the method as described by $\mathrm{Wu}$ et al. (2011) [22] using a UFLC-HPLC system (Shimadzu, Japan). The dextran was dissolved in water and separated by TSKgel G5000PW $(7.5 \mathrm{~mm} \times 30 \mathrm{~cm}$; Tosoh, Shanghai, China) at $60^{\circ} \mathrm{C}$ using distilled water as an eluent 
with a flow rate of $0.6 \mathrm{~mL} / \mathrm{min}$. The polymer was monitored by an RID-10A refractive index detector (Shimadzu, Japan). DLS was performed using a Zetasizer Nanoseries model S4700 (Malvern Instruments, UK). The dextran molecular weight was estimated by DLS [23]. Water was used as a dispersant where the viscosity and reflective index (RI) were $0.8872 \mathrm{cP}$ and 1.33 , respectively, at $25^{\circ} \mathrm{C}$. The purified dextran was dispersed in water to the concentration of $1 \times 10^{-6}-6 \times$ $10^{-6} \mathrm{~g} / \mathrm{mL}$. The hydrodynamic diameter of the dextran was directly read from the instrument. The molecular weight was estimated via empirical mass versus size calibration curves by using the definite molecular weight of globular protein (4.71 $\left.\times 10^{5} \mathrm{kDa}\right)$, linear polymer $\left(1.98 \times 10^{4} \mathrm{kDa}\right)$, brush polymer $\left(1.82 \times 10^{5} \mathrm{kDa}\right)$, and starburst polymer $\left(1.62 \times 10^{7} \mathrm{kDa}\right)$.

2.7. Structural Analysis. Structural analysis of dextran was performed by NMR spectroscopy using an Avance III NMR spectrometer (Bruker). For ${ }^{1} \mathrm{H}$ NMR, $5 \mathrm{mg}$ purified dextran was dissolved in $0.5 \mathrm{~mL}$ of $\mathrm{D}_{2} \mathrm{O}$ and the process was operated at $500 \mathrm{MHz}$ at $40^{\circ} \mathrm{C} .{ }^{13} \mathrm{C} \mathrm{NMR}$ and $2 \mathrm{D} \mathrm{NMR}$, heteronuclear single-quantum coherence (HSQC), and heteronuclear twobond correlation $(\mathrm{H} 2 \mathrm{BC})$ were conducted at $125 \mathrm{MHz}$ and $40^{\circ} \mathrm{C}$.

2.8. Rheological Analysis. To study rheological properties, dextran gels were prepared. The freeze dried dextran was dissolved in distilled water to final concentrations of 2.5 , 5.0 , and $10.0 \%(\mathrm{w} / \mathrm{v})$ to prepare dextran gels. All samples were vigorously mixed at room temperature for $12 \mathrm{~h}$ to ensure the gels had completely swelled. The samples were tested on a plate-plate combination rheometer (Haake Mars Rheometer, 379-0200, Thermo Electron GmBH, Karlsruhe, Germany; rotor: $\mathrm{C} 35 / 1^{\circ}, D=60 \mathrm{~mm}$ ). Two functions of measurement, that is, oscillatory stress sweep and frequency sweep, were used. Oscillatory stress sweep was conducted by fixing the frequency at $1 \mathrm{~Hz}$ while oscillatory frequency sweep experiments were conducted at a fixed shear stress of $1 \mathrm{~Pa}$. $G^{\prime}$ (solid-like structure), $G^{\prime \prime}$ (liquid-like structure), and viscosity of the samples were measured at 25,37 , and $50^{\circ} \mathrm{C}$.

\section{Results and Discussion}

3.1. Bacterial Strain and Identification. W. confusa R003 isolated from sugar cane juice from a sugar factory in Thailand showed rapid growth and slimy mucoid colonies on modified MRS agar after incubation at $30^{\circ} \mathrm{C}$ for $24 \mathrm{~h}$. The $16 \mathrm{~S}$ rDNA sequence showed $99 \%$ sequence similarity to $W$. confusa. The $16 \mathrm{~S}$ rDNA sequence was submitted to the GenBank database with accession number KF312398.

3.2. Dextran Production and Purification. The time course of dextran production by $W$. confusa R003 in modified MRS medium is shown in Figure 1. Dextran production dramatically increased according to cell growth within $8 \mathrm{~h}$ of incubation. The highest dextran amount was detected at $24 \mathrm{~h}(25 \mathrm{~g} / \mathrm{L})$, while the highest OD600 was detected at $12 \mathrm{~h}$. After that incubation time, there was a possibility that $\mathrm{pH}$ and nutrients in the culture medium decreased, leading to a decline phase of the bacteria. However, dextran could still

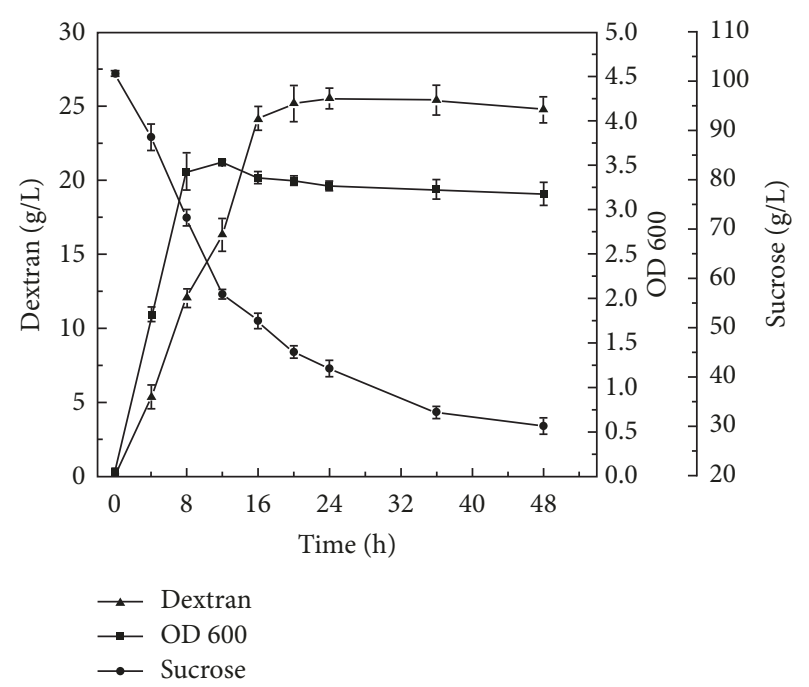

Figure 1: Time course of dextran production, cell growth, and sucrose consumption of $W$. confusa R003 in MRS medium pH 7.5, containing $10 \% \mathrm{w} / \mathrm{v}$ sucrose at $30^{\circ} \mathrm{C}$ with a shaking rate of $125 \mathrm{rpm}$.

be synthesized via dextransucrase until sucrose diminished. The sucrose contents in culture broth dramatically decreased within $0-24 \mathrm{~h}$ and then it has slowly decreased in $24-48 \mathrm{~h}$. At 0,24 , and $48 \mathrm{~h}$, the amount of sucrose was approximately 100,41 , and $30 \mathrm{~g} / \mathrm{L}$, respectively. The high consumption period of sucrose was found in the same range of high dextran production and cell growth. This result suggested that the sucrose was changed to dextran and suitable time for dextran production was $24 \mathrm{~h}$. From previous reports, the initial concentration of sucrose affected the production yield of dextran. In this research, the concentration of sucrose was started at $100 \mathrm{~g} / \mathrm{L}$. According to our preliminary studies, using an initial concentration of sucrose of more than $100 \mathrm{~g} / \mathrm{L}$ contributed to the high viscosity of the culture medium, resulting in difficulty separating bacterial cells from the culture medium, while using an initial concentration of sucrose less than $100 \mathrm{~g} / \mathrm{L}$ resulted in low dextran production yield. In the mechanism of dextran synthesis, glucosyl moieties from sucrose molecules are transferred to the reducing end of the dextran chain [24]. Therefore, the efficiency yield of dextran production could be predicated from the weight ratio of dextran and the initial glucose moiety. W. confusa R003 was able to produce dextran with an efficiency yield $50 \%$. The production yield of the strain was less than the $92.4 \%$ from $W$. confusa Cab3 [25] used to optimize the medium containing $6.06 \%(\mathrm{w} / \mathrm{v})$ sucrose. However, it was higher than the $32 \%$ observed from $W$. cibaria CMGDEX3, which was carried out on MRS medium containing 15\% (w/v) sucrose [1]. Therefore, the results show the potential for dextran production by this strain, which may be further improved by medium optimization and applied on an industrial scale.

3.3. Scanning Electron Microscopy. SEM revealed the surface morphologies of the freeze dried dextrans. At the low magnification of 200x and 500x (Figures 2(a) and 2(b)), it appeared as fibrous groups that folded with each other while, at the higher magnification of 1000x and 5000x (Figures 


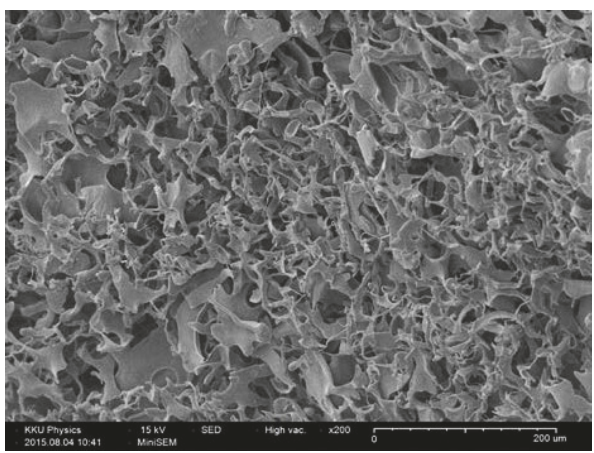

(a)

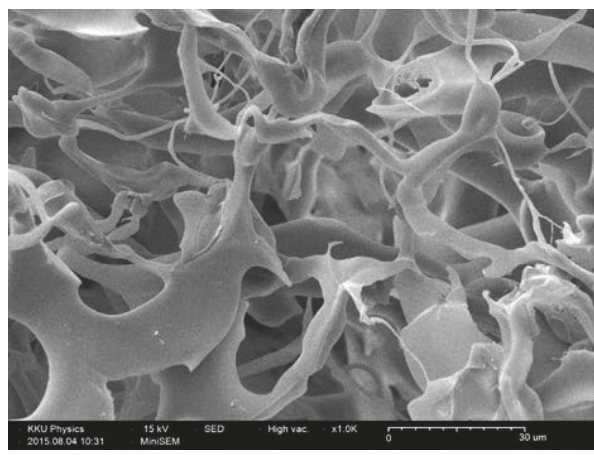

(c)

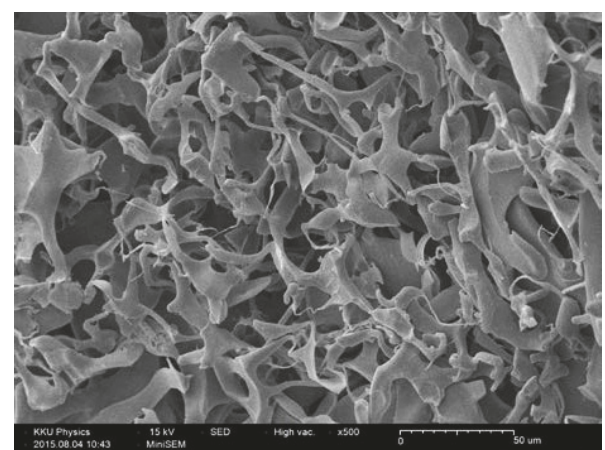

(b)

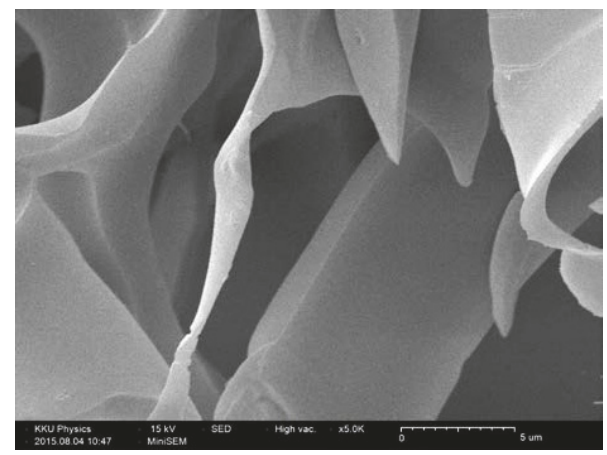

(d)

FIGURE 2: Surface morphology of dextran from W. confusa R003 by scanning electron microscopy (SEM): (a) 200x; (b) 500x; (c) 1000x; (d) 5000x.

2(c) and 2(d)), a network of sheets permeated with pores was observed. This result implied interactions in an aqueous system between the dextran molecules such that their chains were weaved in with nearby molecules due to hydrophobic interactions, while hydrophilic regions formed interactions with water. The surface morphologies may be affected by the method of sample preparation, which would subsequently affect their rheological behaviors. Moreover, this result was different from a previous report on the dextran produced by dextransucrase from Leuconostoc mesenteroides NRRL B-640, which exhibited a cubical or web-like structure [15]. The distinctions in surface morphology of dextrans revealed from SEM might be a result of the differences in their chemical bonding. The $W$. confusa R003 dextran was composed of $2.6 \% \alpha(1 \rightarrow 3)$ branch linkages while L. mesenteroides NRRL B-640 was a linear chain of $\alpha(1 \rightarrow 6)$ linkages. The branched dextran was less soluble in water comparing to a linear dextran. It was possible that the W. confusa R003 dextran has diverged in dispersion character in the solution. Therefore, it exhibited sheet-like structure and was highly porous. Moreover, Zhou et al. (2018) have described that difference in microstructures and surface morphologies result from microorganism strains and monosaccharide composition and structure [26].

3.4. Dextran Molecular Weight. The HPLC results showed that the molecular weight of dextran was greater than $2.0 \times$ $10^{3} \mathrm{kDa}$ since it was eluted in the void volume of the column. However, DLS determination revealed two average molecular weights of $1.0 \times 10^{4} \mathrm{kDa}$. The molecular weight of $1.0 \times$ $10^{4} \mathrm{kDa}$ correlates with previous reports of some dextrans produced from LAB such as L. mesenteroides KIBGE-IB22 and its mutant strain L. mesenteroides KIBGE-IB22 M20, which produced large dextrans with high molecular weights of $1.5-2.0 \times 10^{4}$ and $2.5-4.0 \times 10^{4} \mathrm{kDa}$, respectively [27]. $L$. mesenteroides sp. produced 1.0-4.0 $\times 10^{4} \mathrm{kDa}$ dextran [28]. $W$. confusa Cab3 produced $1.8 \times 10^{4} \mathrm{kDa}$ dextran [18]. However, the aggregation of dextran might have appeared due to hydrophobic and hydrophilic regions within the dextran molecules. Dextran composed of both hydrophobic and hydrophilic regions contributes to interactions in aqueous solution [12].

3.5. Structural Analysis. The ${ }^{1} \mathrm{H}$ NMR spectrum of the dextran is shown in Figure 3(a). The peaks were distributed into two regions, upfield of 3.5-4.0 ppm and downfield of 4.9-5.3 ppm. This was in agreement with the ${ }^{1} \mathrm{H}$ NMR spectrum of dextran where the proton signals at C-2, C$3, \mathrm{C}-4, \mathrm{C}-5$, and C-6 were found in the range of 3-4 ppm while C-1 was found in the $4-6$ ppm region [29]. From the spectrum, two peaks of anomeric protons were observed. The high intensity peak at $4.98 \mathrm{ppm}$ was referred to the anomeric proton of the $\alpha(1 \rightarrow 6)$ linkages in the main chain $[1,4,6,15,30$, 31 ], whereas the low intensity peak at $5.32 \mathrm{ppm}$ represented the anomeric proton of the $\alpha(1 \rightarrow 3)$ branch linkages $[1,4,31]$. A ratio of $97: 3$ was obtained from the integration of the relative intensity of the signal at 4.98 and $5.32 \mathrm{ppm}$. This result suggests that the dextran was composed of $97.4 \% \alpha$ 


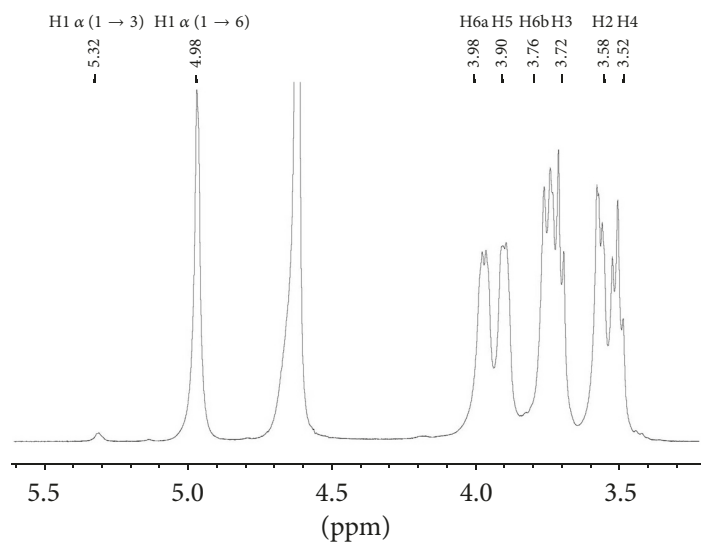

(a)

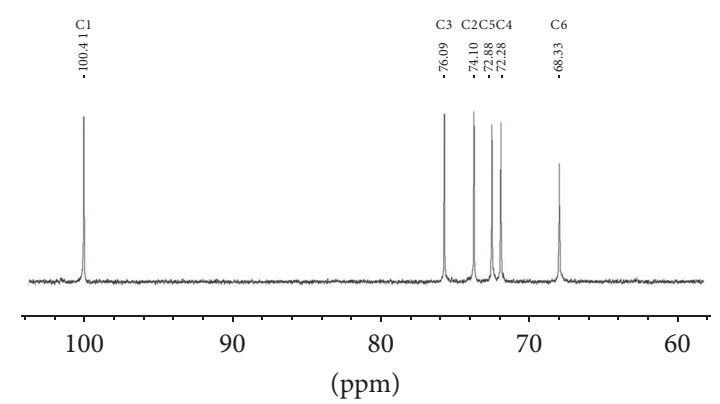

(b)

Figure 3: 1D NMR spectrum of purified dextran from $W$. confusa R003 recorded at $40{ }^{\circ} \mathrm{C}$ in $\mathrm{D}_{2} \mathrm{O}$ : (a) ${ }^{1} \mathrm{H} \mathrm{NMR}(500 \mathrm{MHz})$; (b) ${ }^{13} \mathrm{C} \mathrm{NMR}$ (125 MHz).

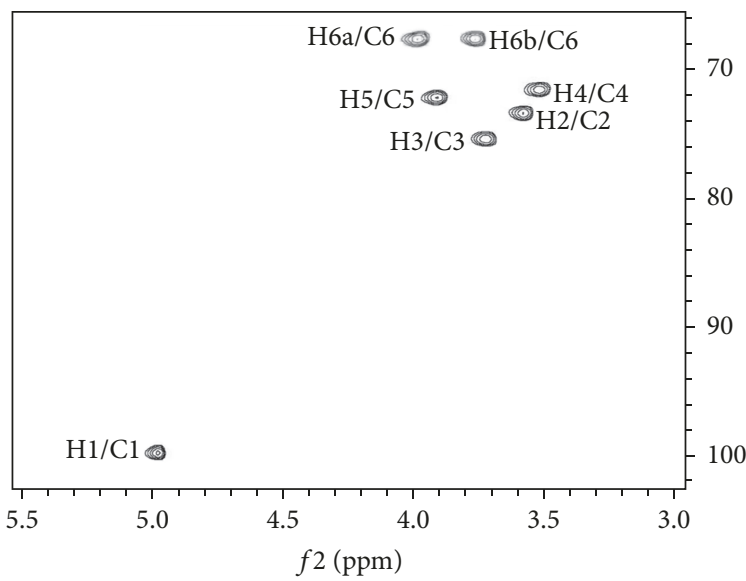

(a)

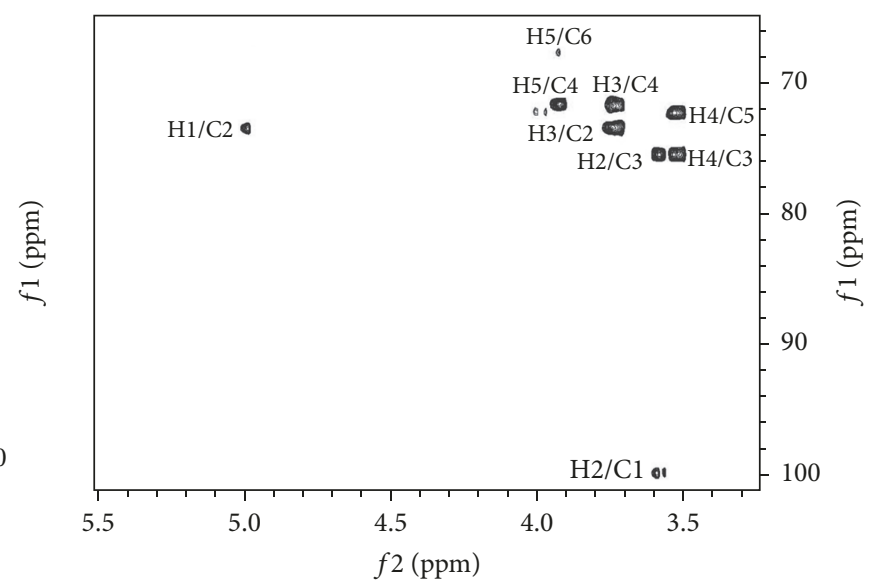

(b)

Figure 4: 2D NMR spectrum of purified dextran from $W$. confusa R003 recorded at $125 \mathrm{MHz}$ in $\mathrm{D}_{2} \mathrm{O}$ at $40^{\circ} \mathrm{C}$ : (a) HSQC spectrum; (b) $\mathrm{H} 2 \mathrm{BC}$ spectrum.

$(1 \rightarrow 6)$ linkages in the main chain and $2.6 \% \alpha(1 \rightarrow 3)$ branch linkages.

The ${ }^{13} \mathrm{C}$ NMR spectrum revealed six peaks appearing around 68-100 ppm (Figure 3(b)). In previous studies, anomeric carbon signals were generally found downfield, in the region of 95-105 ppm [15]. Carbon signals at C-2, C-3, $\mathrm{C}-4$, and C-5 were found in the range of $70-75 \mathrm{ppm}$, while C-6 was found in the upfield region at about $60 \mathrm{ppm}[1,4]$. Moreover, dextran branch linkage signals were found around $75-85 \mathrm{ppm}$ [15]. In this study, the signal at $100.41 \mathrm{ppm}$ was clearly due to the anomeric carbon C-1, while the signal at $68.33 \mathrm{ppm}$ was due to C-6. This peak was also observed at a lower intensity compared to the other peaks since some parts of the $\alpha(1 \rightarrow 6)$ linkages had been replaced by $\alpha(1 \rightarrow 3)$ branches. However, the signal referring to branch linkages around 75-85 ppm was absent due to the small amount of $\alpha$ $(1 \rightarrow 3)$ linkages. To assign the signals at $72.28,72.88,74.10$, and $76.09 \mathrm{ppm}$, the data from 2D NMR were also analyzed.

HSQC and $\mathrm{H} 2 \mathrm{BC}$, which provided the correlation between ${ }^{1} \mathrm{H}$ and ${ }^{13} \mathrm{C}$ direct bond and two bonds, respectively, were used to confirm the structure of the polysaccharide (Figures 4(a) and 4(b)). From the HSQC spectrum, seven protons in the glucose residue were found to correlate. The correlation of ${ }^{1} \mathrm{H}$ at $4.98 \mathrm{ppm}$ and ${ }^{13} \mathrm{C}$ at $100.41 \mathrm{ppm}$ confirmed the presence of $\alpha(1 \rightarrow 6)$ glycosidic bond. Other assignments from the HSQC and $\mathrm{H} 2 \mathrm{BC}$ analysis of each position are presented in Table 1. The NMR results confirmed that the dextran was composed of glucose units linked with 97.4\% $\alpha(1 \rightarrow 6)$ glycosidic bonds and 2.6\% $\alpha(1 \rightarrow 3)$ branches. This finding emphasizes the unique structure of dextrans from the genus Weissella, which have high linearity and low branching.

3.6. Rheological Analysis. The flow behavior of the dextran solutions in water was studied by oscillatory stress sweep at different concentrations, temperatures, and shear stress levels in order to evaluate these effects. As the rheological characteristics of biopolymer solutions are complex and are affected by the experiment conditions, in this study, the frequency of stress was fixed at $1 \mathrm{~Hz}$ while the storage 
TABle 1: Assignment of ${ }^{1} \mathrm{H} /{ }^{13} \mathrm{C}$ chemical shift of dextran from $W$. confusa R003 correlated with dextran from W. confusa E392.

\begin{tabular}{|c|c|c|c|c|c|c|c|}
\hline Atom position & & 1 & 2 & 3 & 4 & 5 & 6 \\
\hline \multirow{2}{*}{ W. confusa R003 } & ${ }^{1} \mathrm{H}$ & 4.98 & 3.58 & 3.72 & 3.52 & 3.90 & $3.76 / 3.98$ \\
\hline & ${ }^{13} \mathrm{C}$ & 100.28 & 74.10 & 76.09 & 72.28 & 72.88 & 68.33 \\
\hline \multirow{2}{*}{ W. confusa $\mathrm{E} 392^{\mathrm{a}}$} & ${ }^{1} \mathrm{H}$ & 4.98 & 3.58 & 3.73 & 3.52 & 3.91 & $3.77 / 3.98$ \\
\hline & ${ }^{13} \mathrm{C}$ & 99.3 & 72.9 & 74.8 & 71.2 & 71.8 & 67.3 \\
\hline
\end{tabular}

${ }^{\mathrm{a}}$ Maina et al. [4].

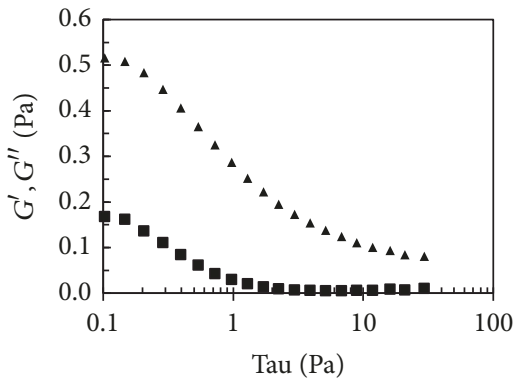

(a)

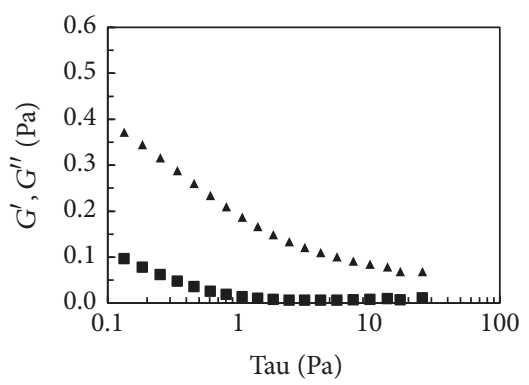

(d)

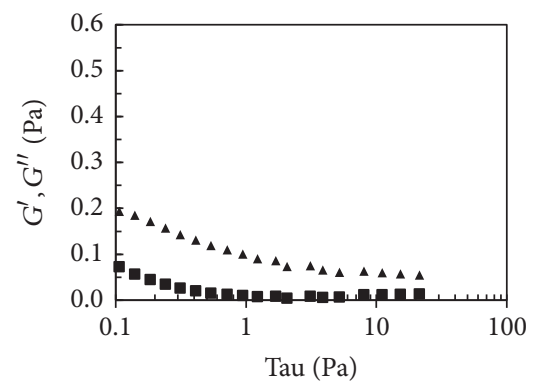

(g)

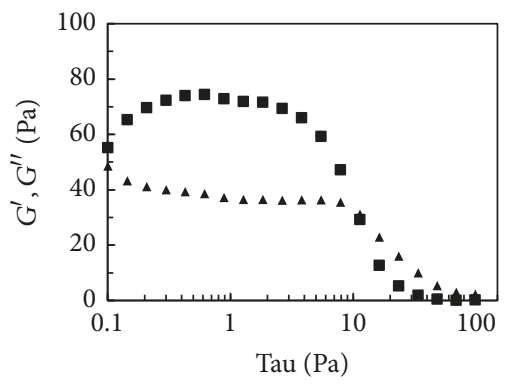

(b)

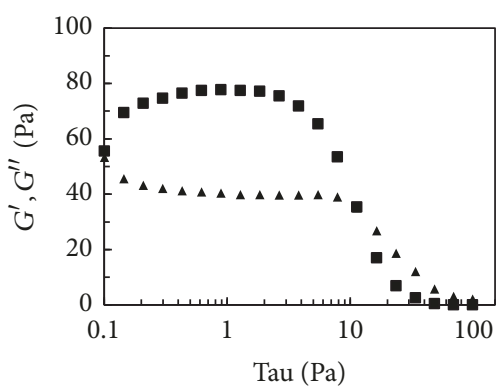

(e)

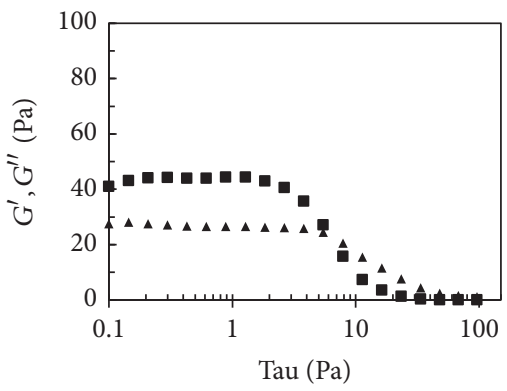

(h)

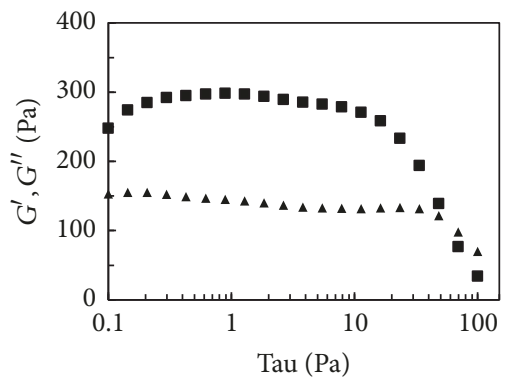

(c)

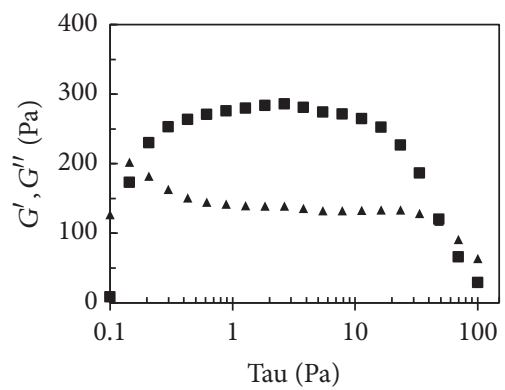

(f)

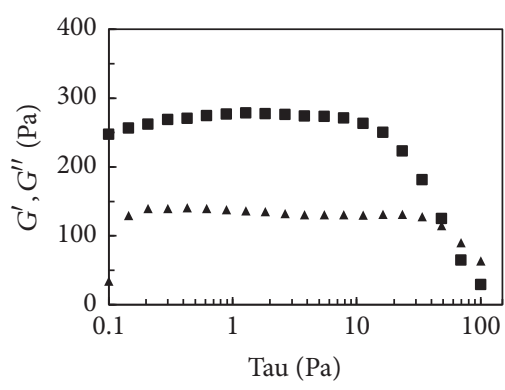

(i)

Figure 5: Elastic moduli, $G^{\prime}(\mathbf{\square})$, and viscous moduli, $G^{\prime \prime}(\mathbf{\Delta})$, as a function of shear of the purified dextran from W. confusa R003: (a) 2.5\% w/v, $25^{\circ} \mathrm{C}$; (b) $5.0 \% \mathrm{w} / \mathrm{v}, 25^{\circ} \mathrm{C}$; (c) $10.0 \% \mathrm{w} / \mathrm{v}, 25^{\circ} \mathrm{C}$; (d) $2.5 \% \mathrm{w} / \mathrm{v}, 37^{\circ} \mathrm{C}$; (e) $5.0 \% \mathrm{w} / \mathrm{v}, 37^{\circ} \mathrm{C}$; (f) $10.0 \% \mathrm{w} / \mathrm{v}, 37^{\circ} \mathrm{C}$; (g) $2.5 \% \mathrm{w} / \mathrm{v}, 50^{\circ} \mathrm{C}$; (h) $5.0 \% \mathrm{w} / \mathrm{v}, 50^{\circ} \mathrm{C}$; (i) $10.0 \% \mathrm{w} / \mathrm{v}, 50^{\circ} \mathrm{C}$.

modulus $\left(G^{\prime}\right)$ and loss modulus $\left(G^{\prime \prime}\right)$ were monitored in the ranges of shear (Tua) $0.1-100.0 \mathrm{~Pa}$. The results are shown in Figures 5(a)-5(i).

The aqueous dextran exhibited liquid-like behavior at $2.5 \% \mathrm{w} / \mathrm{v}$ at the temperatures of 25,37 , and $50^{\circ} \mathrm{C}$ (Figures $5(\mathrm{a}), 5(\mathrm{~d})$, and $5(\mathrm{~g}))$ because of the distinctive $G^{\prime \prime}$ over $G^{\prime}$ observed in the entire range of the applied shear stress. At $25^{\circ} \mathrm{C}$, both $G^{\prime}$ and $G^{\prime \prime}$ tended to decrease successively as the shear rate increased; $G^{\prime}$ started to approach zero around a shear stress of 2.2 Pa. This pattern of the $G^{\prime}$ and $G^{\prime \prime}$ profile was observed when the temperature was increased to $37^{\circ} \mathrm{C}$ and $50^{\circ} \mathrm{C}$ at this concentration. This confirmed that the dextran absolutely behaved like a liquid at this concentration. An effect of temperature was found as a reduction in the modulus $\left(G^{\prime}\right.$ and $\left.G^{\prime \prime}\right)$ when the temperature increased. Comparing the modulus at the initial shear stress showed that $G^{\prime \prime}$ was $0.52,0.37$, and $0.12 \mathrm{~Pa}$ at $25^{\circ}, 37^{\circ} \mathrm{C}$, and $50^{\circ} \mathrm{C}$, respectively, while $G^{\prime}$ was $0.17,0.09$, and $0.07 \mathrm{~Pa}$ at $25^{\circ} \mathrm{C}, 37^{\circ} \mathrm{C}$, and $50^{\circ} \mathrm{C}$, respectively.

Increasing the dextran concentration led to a transformation from liquid-like to solid-like behavior. At $5.0 \% \mathrm{w} / \mathrm{v}$ dextran, the $G^{\prime}$ and $G^{\prime \prime}$ profile was markedly different from 
that of $2.5 \% \mathrm{w} / \mathrm{v}$ dextran (Figures 5(b), 5(e), and 5(h)). At the beginning, with low stress, a linear viscoelastic region (LVR) and then a crossover between $G^{\prime}$ and $G^{\prime \prime}$ were observed. In the LVR range, $G^{\prime}$ overcame $G^{\prime \prime}$ after starting to apply stress and then successively scrolled down to the crossover point. After this point, $G^{\prime \prime}$ increased over $G^{\prime}$. This indicates that the aqueous dextran changed from solid-like to liquid-like behavior.

Therefore, at $5.0 \% \mathrm{w} / \mathrm{v}$, dextran acted as a viscoelastic material depending on the stress. At a low level of stress, around $0.1-10.0 \mathrm{~Pa}$, solid-like behavior was prominent, while liquid-like behavior was apparent with a high stress, around 10-100 Pa. The existence of crossover denoted that dextran has a dense structure, which resulted from network interactions between dextran-dextran molecules and dextranwater molecules. When a small amount of shear stress was applied, the samples were able to absorb most of energy while maintaining their structure without deformation. When the applied shear stress reached a yield point, the structure of the samples started to break down and eventually flowed. The prior reductions in modulus $\left(G^{\prime}\right.$ and $\left.G^{\prime \prime}\right)$ indicated that the structure of the dextran began to break down. However, it may be said that the crossover points were the yield point of the aqueous sample [32]. At $50^{\circ} \mathrm{C}$, it rapidly deformed, comparing to the behavior at 25 and $37^{\circ} \mathrm{C}$. This may have occurred since, at $50^{\circ} \mathrm{C}$, the dextran molecules carried a lot of thermal energy and flow easily occurred although a small amount of stress was applied. The apparent shear stress, strain, and moduli $\left(G^{\prime}\right.$ and $\left.G^{\prime \prime}\right)$ at the yield point (crossover point) were $10.69 \mathrm{~Pa}\left(\mathrm{\gamma}=24.11 \%\right.$; $\left.G^{\prime}=G^{\prime \prime}=32.22 \mathrm{~Pa}\right)$, $11.44 \mathrm{~Pa}\left(\mathrm{\gamma}=23.32 \% ; G^{\prime}=G^{\prime \prime}=34.99 \mathrm{~Pa}\right)$, and $6.16 \mathrm{~Pa}(\mathrm{\gamma}=$ $19.38 \% ; G^{\prime}=G^{\prime \prime}=23.26 \mathrm{~Pa}$ ) at 25,37 , and $50^{\circ} \mathrm{C}$, respectively. Moreover, the moduli in the LVR from $25^{\circ} \mathrm{C}$ was similar to $37^{\circ} \mathrm{C}$ but markedly higher than the moduli in the LVR at $50^{\circ} \mathrm{C}$. It was interesting that the yield point did not decrease when the temperature was increased. The yield stress at $37^{\circ} \mathrm{C}$ was higher than that at $25^{\circ} \mathrm{C}$, even though the dextran molecules had greater thermal energy. These results suggest that the dextran solution at $37^{\circ} \mathrm{C}$ was able to maintain structure more than the aqueous dextran at $25^{\circ} \mathrm{C}$. This phenomenon can be explained in terms of the solubility of the polymer. This dextran has a high molecular weight and branches, so increasing the temperature promoted the solubility of the sample. Normally, dextran in aqueous solution forms a gel via an entanglement network [12]. In an entanglement network, most of the interactions occur via interlacing polymeric chains. Moreover, ionic/hydrophobic interactions and $\mathrm{H}-$ bonds are occasionally found in the network. Hence, factors such as the degree of polymerization and the length of the polymeric chain could affect the solubility and rheological behavior of the polymer in an aqueous system. It is possible that dextran solubility at $25^{\circ} \mathrm{C}$ was less than that at $37^{\circ} \mathrm{C}$, resulting in weak entanglement networks and thus a lower crossover point at $25^{\circ} \mathrm{C}$ compared to $37^{\circ} \mathrm{C}$.

High dextran concentrations led to a more solid-like or stronger gel character, that is, $10 \% \mathrm{w} / \mathrm{v}$ dextran (Figures $5(\mathrm{c}$ ), $5(\mathrm{f})$, and $5(\mathrm{i}))$. The LVR of $10 \% \mathrm{w} / \mathrm{v}$ dextran was longer than that of $5 \% \mathrm{w} / \mathrm{v}$ dextran; likewise, the yield stress of $10 \% \mathrm{w} / \mathrm{v}$ dextran was higher than that of $5 \% \mathrm{w} / \mathrm{v}$ dextran. The apparent

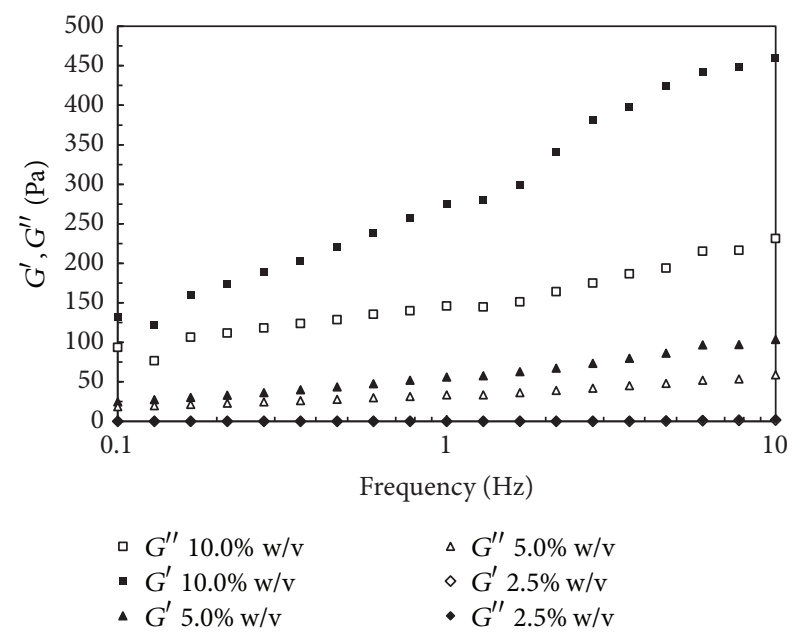

Figure 6: Elastic moduli, $G^{\prime}$, and viscous moduli, $G^{\prime \prime}$, as a function of frequency at $37^{\circ} \mathrm{C}$ of the purified dextran from $W$. confusa R003 at the concentration of $2.5,5.0$, and $10.0 \% \mathrm{w} / \mathrm{v}$.

shear stress, strain, and moduli $\left(G^{\prime}\right.$ and $\left.G^{\prime \prime}\right)$ at the yield point (crossover point) were $55.89 \mathrm{~Pa}\left(\mathrm{\gamma}=36.78 \%\right.$; $G^{\prime}=G^{\prime \prime}=$ $114.9 \mathrm{~Pa}), 11.44 \mathrm{~Pa}\left(\mathrm{\gamma}=23.32 \% ; \mathrm{G}^{\prime}=\mathrm{G}^{\prime \prime}=34.99 \mathrm{~Pa}\right)$, and $52.76 \mathrm{~Pa}\left(\mathrm{\gamma}=35.58 \% ; \mathrm{G}^{\prime}=\mathrm{G}^{\prime \prime}=111.2 \mathrm{~Pa}\right)$ at 25,37 , and $50^{\circ} \mathrm{C}$, respectively.

From these results, it was concluded that there are three parameters, that is, concentration, temperature, and stress, which affect the rheological behavior of the dextran from $W$. confusa R003. Low concentration dextran at $2.5 \% \mathrm{w} / \mathrm{v}$ behaved like a liquid, while, at 5 and $10 \% \mathrm{w} / \mathrm{v}$, it behaved like a viscoelastic material. A higher dextran concentration caused more gelation. The optimum temperature for maintaining the structure was $37^{\circ} \mathrm{C}$. The rheological behavior of high concentration of 5 and $10 \% \mathrm{w} / \mathrm{v}$ dextran was affected by increasing shear stress, which led to the transformation to liquid-like behavior.

The fluid structure of the purified dextran was also analyzed by frequency sweep in the frequency range of $0.1-10.0 \mathrm{~Hz}$ in the temperature of 25,37 , and $50^{\circ} \mathrm{C}$. The data obtained at the temperature of $37^{\circ} \mathrm{C}$ was selected as representative results (Figure 6). Based on the results, the liquidlike behavior of dextran at $2.5 \% \mathrm{w} / \mathrm{v}$ was confirmed. The elastic modulus, $G^{\prime}$, and viscous modulus, $G^{\prime \prime}$, approached zero in the entire frequency range. An increase in the polymer concentration promoted its gelation. In the aqueous solutions of 5.0 and $10.0 \% \mathrm{w} / \mathrm{v}$ dextran, the dextran expressed typical solid-like behavior in which $G^{\prime}$ dominated over $G^{\prime \prime}$ in the entire frequency range at both concentrations. $G^{\prime}$ was more frequency dependent particularly in the high frequency region. Especially for $10 \% \mathrm{w} / \mathrm{v}$ dextran, the slope of the line in the frequency range of $2.1-10.0 \mathrm{~Hz}$ was higher than the slope of the line in the range of $0.1-1.0 \mathrm{~Hz}$. This result indicates that the polymer tended to shift from solid to liquid in the high frequency field. The strong frequency dependence of $G^{\prime}$ also indicated that its fluid structure was formed via an entanglement network [12]. This result provides beneficial data that can be applied to processing this dextran for use in commercial applications. 


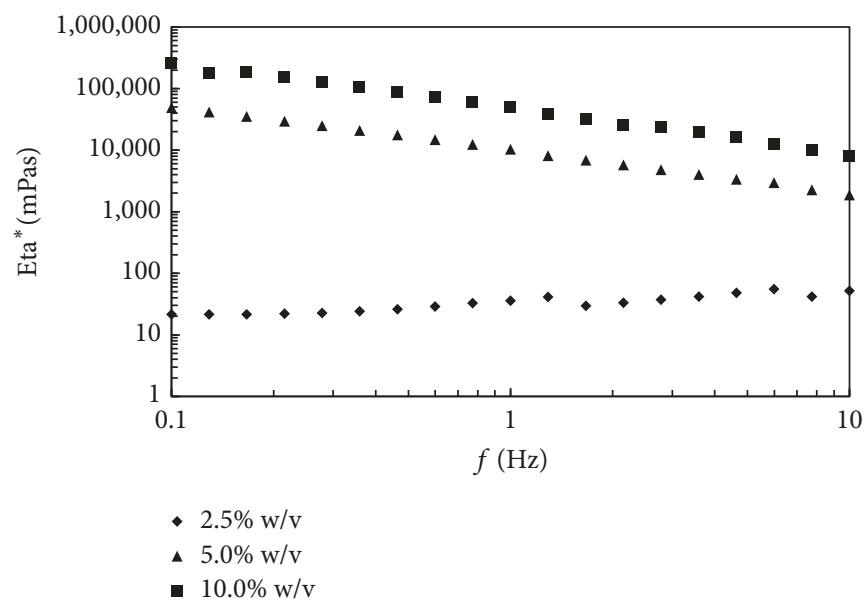

(a)

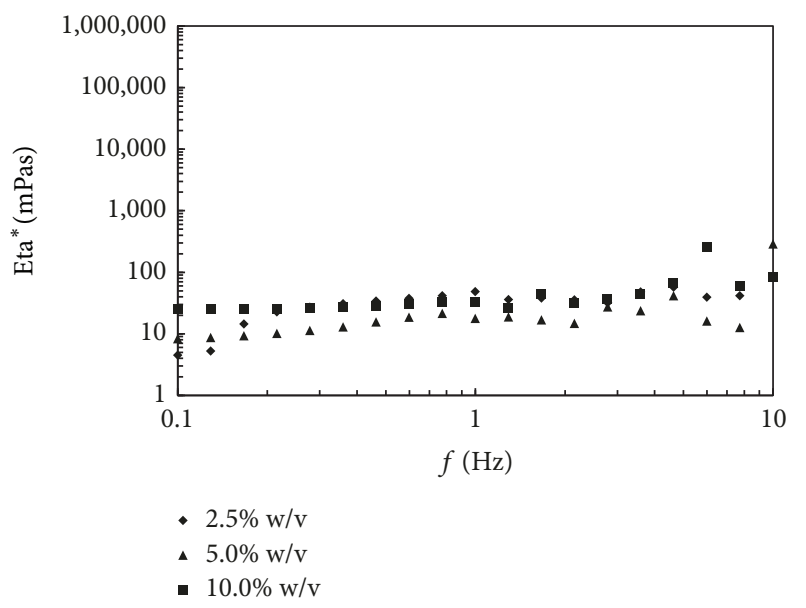

(b)

Figure 7: Complex viscosity, Eta ${ }^{*}$, as a function of frequency: (a) the purified dextran from W. confusa R003; (b) commercial dextran T2000.

The complex viscosity (Eta ${ }^{*}$ ) of the dextran is depicted in Figure 7(a). The result very clearly shows that the viscosity of the aqueous polymer decreased with a decrease in the polymer concentration. However, the progressive increase in viscosity was not proportional with the increase in concentration. An increase in the dextran concentration from $2.5 \% \mathrm{w} / \mathrm{v}$ to $5.0 \% \mathrm{w} / \mathrm{v}$ led to a large increase in viscosity, while, from $5.0 \% \mathrm{w} / \mathrm{v}$ to $10.0 \% \mathrm{w} / \mathrm{v}$ dextran, the viscosity increased to a lesser extent. Considering a middle point frequency at $1.0 \mathrm{~Hz}$, the observed viscosity of $10 \% \mathrm{w} / \mathrm{v}$ dextran was around 4.7 and 1,300 times higher than that of 5.0 and $2.5 \% \mathrm{w} / \mathrm{v}$ dextran, respectively. Moreover, the viscosity trend from $2.5 \% \mathrm{w} / \mathrm{v}$ was also different than the others since it was slightly stable in the entire frequency range. The observed viscosity of $5.0 \% \mathrm{w} / \mathrm{v}$ and $10.0 \% \mathrm{w} / \mathrm{v}$ dextran was successively decreased as the frequency increased. This result also indicates that a concentration between 2.5 and $5.0 \% \mathrm{w} / \mathrm{v}$ might be in the critical range in which dextran is able to shift from liquid-like to solid-like behavior. Comparing the viscosity of the commercial dextran T2000 (Figure 7(b)), all concentrations $(2.5-10 \% \mathrm{w} / \mathrm{v})$ of the polymer exhibited low viscosity and the same pattern of the viscosity profile. These results are similar to the viscosity profile of $2.5 \% \mathrm{w} / \mathrm{v}$ dextran from $W$. confusa R003. This result indicates that the gelation of dextran T2000 is not promoted by increasing the concentration in the range of $2.5-10.0 \% \mathrm{w} / \mathrm{v}$. Dextran T2000 has a molecular mass around $2000 \mathrm{kDa}$ and is produced by Leuconostoc mesenteroides. Usually, dextrans produced from L. mesenteroides are linear with few branches. A previous study reported that the dextrans from L. mesenteroides NRRL B-640 and L. mesenteroides NRRL AAl are linear without branches $[15,28]$. Meanwhile the dextransucrase from $L$. mesenteroides FT045B synthesizes dextran comprised of only $2.1 \% \alpha(1 \rightarrow 3)$ branch linkages and $97.9 \% \alpha(1 \rightarrow 6)$ linkages in the main chain [6]. The highly linear dextran from $L$. mesenteroides resulted in high solubility in aqueous solution and low viscosity. This characteristic is different from the observations on $W$. confusa R003 dextran, in which the viscosity was very sensitive to the concentration. This might be due to differences in the molecular weight as well as branch patterns. W. confusa R003 dextran has a higher molecular weight, with more than $2000 \mathrm{kDa}$ and is composed of $2.6 \% \alpha(1 \rightarrow 3)$ branch linkages and $97.4 \% \alpha(1 \rightarrow 6)$ linkages. This led to differences from the rheological properties of the dextran from $W$. confusa R003. Due to its high viscosity and ability to behave as a viscoelastic material, it can be used as a gelling agent in commercial applications.

\section{Conclusion}

Dextran tended to have high attention for commercial applications because of the diverse properties depending on their structures and it can be employed in several fields. In this work, W. confusa R003 has expressed the potentiality for dextran production with the $50 \%$ efficiency yield and this was expected to improve in the further study. The results from structural analysis have pointed that the R003 dextran was the high molecular mass and low branched biopolymer. With the apparent properties with $10^{4} \mathrm{kDa}$ in size and $2.6 \% \alpha(1 \rightarrow 3)$ branches, this dextran carried the distinct morphology and the rheological feature from other dextrans. The sheet-like and high porous structure resulted in the ability to hold water and formation of the gel. The flow behavior of dextran solution was influenced by the concentration, temperature, and shear level. The dextran exhibited absolutely liquid at $2.5 \%(\mathrm{w} / \mathrm{v})$ while at $5.0 \%$ and $10 \%(\mathrm{w} / \mathrm{v})$ exhibited both gel- and liquid-like behavior. It also showed noticeably higher viscosity than the commercial dextran T2000. According to the properties of the W. confusa R003 dextran, it may be suitable for use as a food additive or in hydrogel preparations for utilization in the medical field. Moreover, the oligosaccharides generating from enzymatic hydrolysis of this dextran may be used as being prebiotic.

\section{Conflicts of Interest}

The authors declare that there are no conflicts of interest regarding the publication of this paper. 


\section{Acknowledgments}

The authors would like to thank The Royal Golden Jubilee Ph.D. Program for financial support. They also would like to thank the Department of Biochemistry, Faculty of Science, Khon Kaen University, for the facilities and instruments that were used in this research. They are also grateful to Mitr Phol Sugarcane Research Center Co. Ltd., Thailand, for the cooperation.

\section{References}

[1] R. Z. Ahmed, K. Siddiqui, M. Arman, and N. Ahmed, "Characterization of high molecular weight dextran produced by Weissella cibaria CMGDEX3," Carbohydrate Polymers, vol. 90, no. 1, pp. 441-446, 2012.

[2] M.-S. Bounaix, H. Robert, V. Gabriel et al., "Characterization of dextran-producing Weissella strains isolated from sourdoughs and evidence of constitutive dextransucrase expression," FEMS Microbiology Letters, vol. 311, no. 1, pp. 18-26, 2010.

[3] S. Shukla and A. Goyal, "16S rRNA-based identification of a glucan-hyperproducing weissella confusa," Enzyme Research, vol. 2011, Article ID 250842, 10 pages, 2011.

[4] N. H. Maina, M. Tenkanen, H. Maaheimo, R. Juvonen, and L. Virkki, "NMR spectroscopic analysis of exopolysaccharides produced by Leuconostoc citreum and Weissella confusa," Carbohydrate Research, vol. 343, no. 9, pp. 1446-1455, 2008.

[5] D. Kim, J. F. Robyt, S.-Y. Lee, J.-H. Lee, and Y.-M. Kim, "Dextran molecular size and degree of branching as a function of sucrose concentration, $\mathrm{pH}$, and temperature of reaction of Leuconostoc mesenteroides B-512FMCM dextransucrase," Carbohydrate Research, vol. 338, no. 11, pp. 1183-1189, 2003.

[6] M. H. P. B. Vettori, S. M. M. Franchetti, and J. Contiero, "Structural characterization of a new dextran with a low degree of branching produced by Leuconostoc mesenteroides FT045B dextransucrase," Carbohydrate Polymers, vol. 88, no. 4, pp. 1440-1444, 2012.

[7] K. Katina, N. H. Maina, R. Juvonen et al., "In situ production and analysis of Weissella confusa dextran in wheat sourdough," Food Microbiology, vol. 26, no. 7, pp. 734-743, 2009.

[8] F. Sarwat, S. A. U. Qader, A. Aman, and N. Ahmed, "Production \& characterization of a unique dextran from an indigenous Leuconostoc mesenteroides CMG713," International Journal of Biological Sciences, vol. 4, no. 6, pp. 379-386, 2008.

[9] T. Heinze, T. Liebert, B. Heublein et al., "Functional Polymers Based on Dextran," in Polysaccharides II, D. Klemm, Ed., vol. 205, pp. 199-291, Springer, Berlin, Germany, 2006.

[10] S. Patel and A. Goyal, "Functional oligosaccharides: production, properties and applications," World Journal of Microbiology and Biotechnology, vol. 27, no. 5, pp. 1119-1128, 2011.

[11] A. S. Hoffman, "Hydrogels for biomedical applications," Advanced Drug Delivery Reviews, vol. 54, no. 1, pp. 3-12, 2002.

[12] P. A. Padmanabhan, D.-S. Kim, D. Pak, and S. J. Sim, "Rheology and gelation of water-insoluble dextran from Leuconostoc mesenteroides NRRL B-523," Carbohydrate Polymers, vol. 53, no. 4, pp. 459-468, 2003.

[13] R. D. McCurdy, H. D. Goff, D. W. Stanley, and A. P. Stone, "Rheological properties of dextran related to food applications," Topics in Catalysis, vol. 8, no. 6, pp. 609-623, 1994.

[14] S. Patel, N. Kasoju, U. Bora, and A. Goyal, "Structural analysis and biomedical applications of dextran produced by a new isolate Pediococcus pentosaceus screened from biodiversity hot spot Assam," Bioresource Technology, vol. 101, no. 17, pp. 68526855, 2010.

[15] R. K. Purama, P. Goswami, A. T. Khan, and A. Goyal, "Structural analysis and properties of dext ran produced by Leuconostoc mesenteroides NRRL B-640," Carbohydrate Polymers, vol. 76, no. 1, pp. 30-34, 2009.

[16] K. Zarour, M. G. Llamas, A. Prieto et al., "Rheology and bioactivity of high molecular weight dextrans synthesised by lactic acid bacteria," Carbohydrate Polymers, vol. 174, pp. 646657, 2017.

[17] M. Naessens, A. Cerdobbel, W. Soetaert, and E. J. Vandamme, "Leuconostoc dextransucrase and dextran: Production, properties and applications," Journal of Chemical Technology and Biotechnology, vol. 80, no. 8, pp. 845-860, 2005.

[18] S. Shukla, Q. Shi, N. H. Maina, M. Juvonen, M. Tenkanen, and A. Goyal, "Weissella confusa Cab3 dextransucrase: Properties and in vitro synthesis of dextran and glucooligosaccharides," Carbohydrate Polymers, vol. 101, no. 1, pp. 554-564, 2014.

[19] N. Milintawisamai, S. Niamsanit, C. Ngasan, U. Pliansinchai, and P. Weerathaworn, "Dextran producing microorganisms from Mitr Phuveing sugar factory, Thailand," Sugar Tech, vol. 11, no. 2, pp. 196-199, 2009.

[20] J. Brosius, T. J. Dull, D. D. Sleeter, and H. F. Noller, "Gene organization and primary structure of a ribosomal RNA operon from Escherichia coli," Journal of Molecular Biology, vol. 148, no. 2, pp. 107-127, 1981.

[21] J. De Man, D. Rogosa, and M. E. Sharpe, "A medium for the cultivation of Lactobacilli," Journal of Applied Bacteriology, vol. 23, no. 1, pp. 130-135, 1960.

[22] D.-T. Wu, H.-B. Zhang, L.-J. Huang, and X.-Q. Hu, "Purification and characterization of extracellular dextranase from a novel producer, Hypocrea lixii F1002, and its use in oligodextran production," Process Biochemistry, vol. 46, no. 10, pp. 1942-1950, 2011.

[23] B. J. Berne and R. Pecora, Dynamic Light Scattering: with Applications to Chemistry, Biology, and Physics, Courier Corporation, 1976.

[24] J. F. Robyt, S.-H. Yoon, and R. Mukerjea, "Dextransucrase and the mechanism for dextran biosynthesis," Carbohydrate Research, vol. 343, no. 18, pp. 3039-3048, 2008.

[25] S. Shukla and A. Goyal, "Medium optimization of fermentation for enhanced dextran production from weissella confusa Cab3 by statistical methods," Current Biotechnology, vol. 2, no. 1, pp. 39-46, 2013.

[26] Q. Zhou, F. Feng, Y. Yang et al., "Characterization of a dextran produced by Leuconostoc pseudomesenteroides XG5 from homemade wine," International Journal of Biological Macromolecules, vol. 107, pp. 2234-2241, 2018.

[27] N. N. Siddiqui, A. Aman, A. Silipo, S. A. U. Qader, and A. Molinaro, "Structural analysis and characterization of dextran produced by wild and mutant strains of Leuconostoc mesenteroides," Carbohydrate Polymers, vol. 99, pp. 331-338, 2014.

[28] A. Aman, N. N. Siddiqui, and S. A. U. Qader, "Characterization and potential applications of high molecular weight dextran produced by Leuconostoc mesenteroides AA1," Carbohydrate Polymers, vol. 87, no. 1, pp. 910-915, 2012.

[29] R. L. Sidebotham, "Dextrans," Advances in Carbohydrate Chemistry and Biochemistry, vol. 30, pp. 371-444, 1974.

[30] W. Bejar, V. Gabriel, M. Amari et al., "Characterization of glucansucrase and dextran from Weissella sp. TN610 with 
potential as safe food additives," International Journal of Biological Macromolecules, vol. 52, no. 1, pp. 125-132, 2013.

[31] M.-S. Bounaix, V. Gabriel, S. Morel et al., "Biodiversity of exopolysaccharides produced from sucrose by sourdough lactic acid bacteria," Journal of Agricultural and Food Chemistry, vol. 57, no. 22, pp. 10889-10897, 2009.

[32] W. Y. Shih, W.-H. Shih, and I. A. Aksay, "Elastic and yield behavior of strongly flocculated colloids," Journal of the American Ceramic Society, vol. 82, no. 3, pp. 616-624, 1999. 


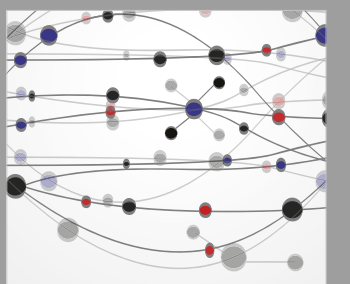

The Scientific World Journal
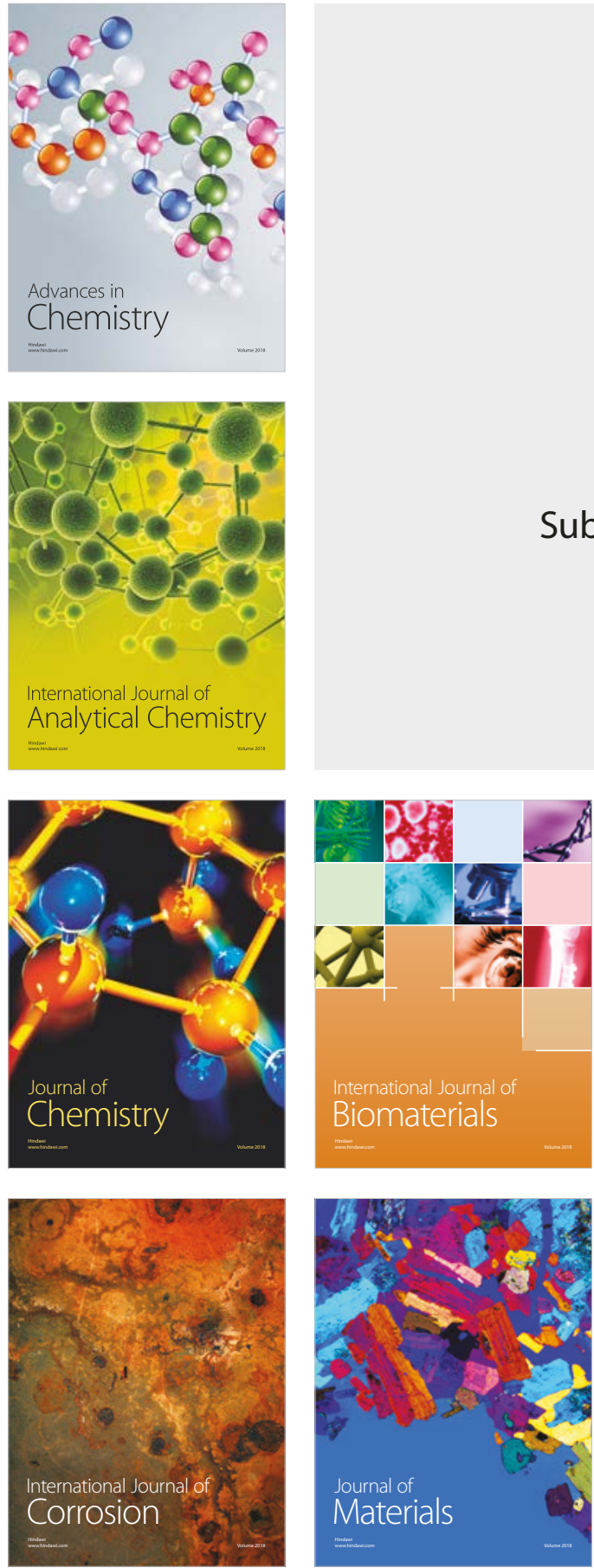

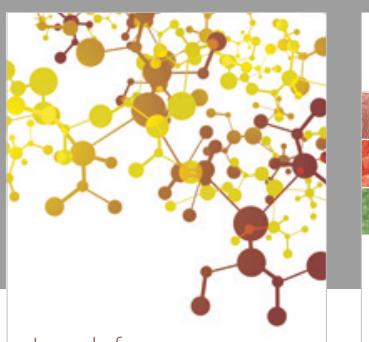

Journal of

Applied Chemistry
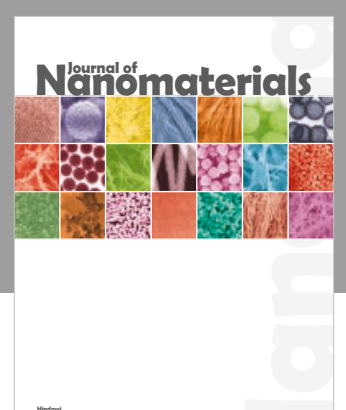

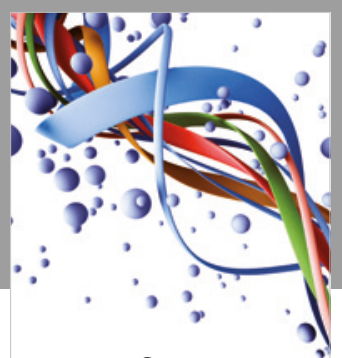

Scientifica

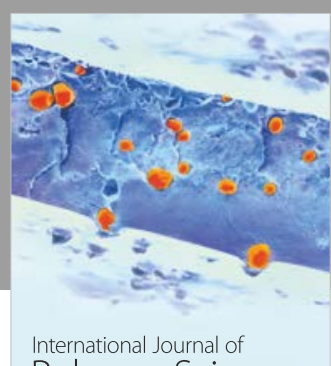

Polymer Science

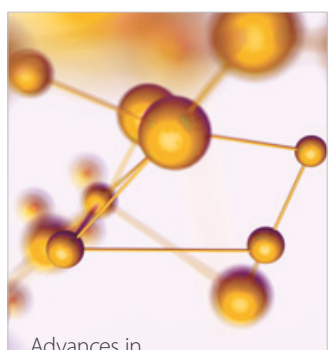

Physical Chemistry
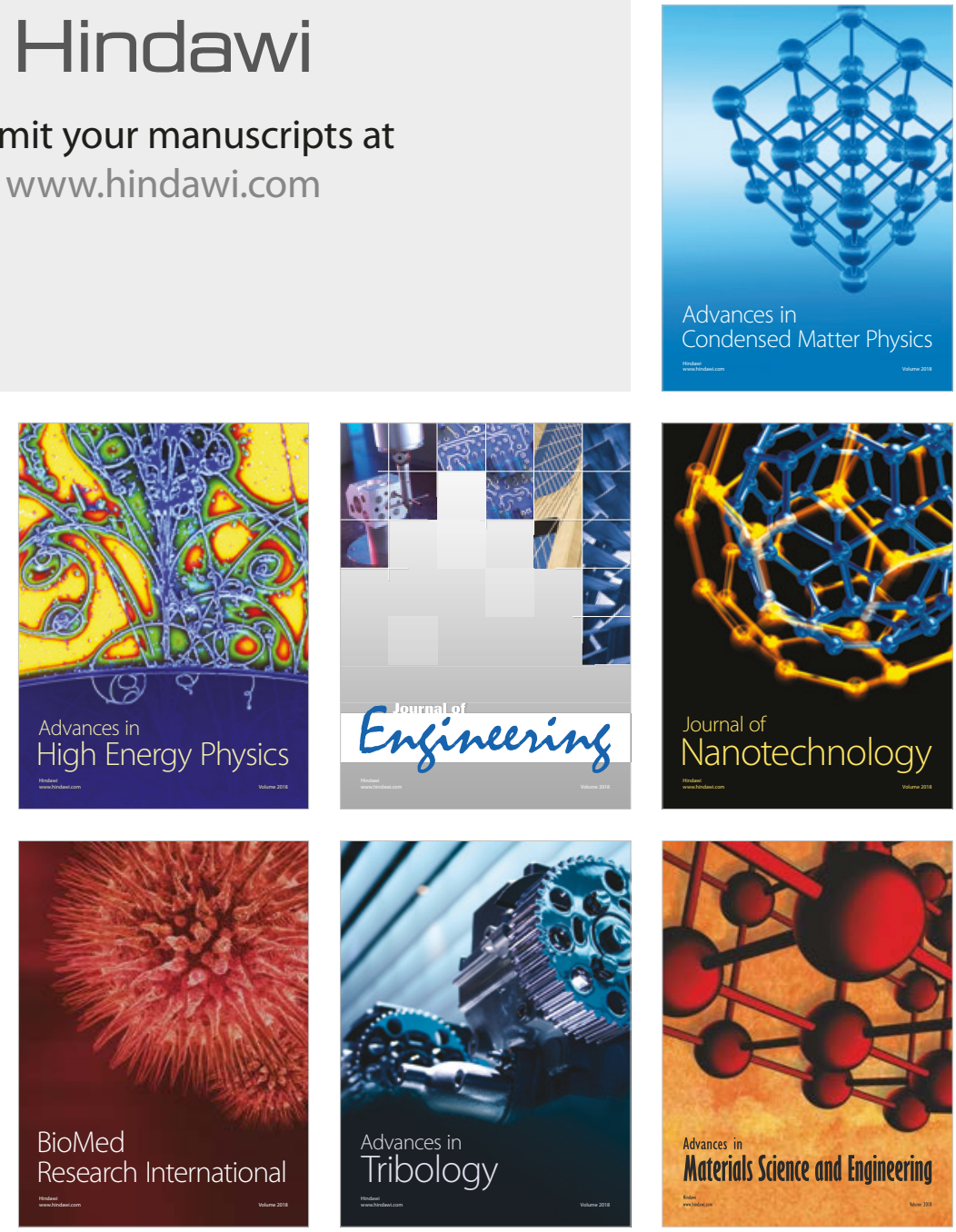